\title{
Detection of chromosomal abnormalities and the 22q11 microdeletion in fetuses with congenital heart defects
}

\author{
WEI LV and SHUYU WANG
}

Department of Genetics, Beijing Obstetrics and Gynecology Hospital, Capital Medical University, Beijing 100026, P.R. China

Received November 27, 2013; Accepted June 5, 2014

DOI: $10.3892 / \mathrm{mmr} .2014 .2564$

\begin{abstract}
Chromosomal abnormalities and the 22q11 microdeletion are implicated in congenital heart defects (CHDs). This study was designed to detect these abnormalities in fetuses and determine the effect of genetic factors on CHD etiology. Between January 2010 and December 2011, 113 fetuses with CHD treated at the Beijing Obstetrics and Gynecology Hospital were investigated, using chromosome karyotyping of either amniotic fluid cell or umbilical cord blood cell samples. Fetuses with a normal result were then investigated for the 22 q11 microdeletion by fluorescence in situ hybridization. Of the 113 patients, $12(10.6 \%)$ exhibited chromosomal abnormalities, while $6(5.3 \%)$ of the remaining 101 cases presented with a 22q11 microdeletion. The incidence of chromosomal abnormalities was significantly higher in the group of fetuses presenting with extracardiac malformations in addition to CHD ( $\mathrm{P}<0.001)$, although the detection of the $22 \mathrm{q} 11$ microdeletion was not significantly different between the two groups $(\mathrm{P}=0.583)$. In addition, all fetuses with the $22 \mathrm{q} 11$ microdeletion occurred de novo. In conclusion, genetic factors are important in the etiology of CHD. Where fetuses present with cardiac defects, additional chromosomal analysis is required to detect extracardiac abnormalities. Fetuses with heart defects should also be considered for $22 \mathrm{q} 11$ microdeletion detection to evaluate fetal prognosis, particularly prior to surgery.
\end{abstract}

\section{Introduction}

Congenital heart defects (CHDs) are among the most common malformations in live-born infants. Complicated structural and functional cardiovascular fetal malformations have high rates of mortality and morbidity, and may result in fetal, neonatal or adolescent fatality, stillbirth, preterm labor or

Correspondence to: Dr Shuyu Wang, Department of Genetics, Beijing Obstetrics and Gynecology Hospital, Capital Medical University, No. 251 Yaojiayuan Road, Chaoyang District, Beijing 100026, P.R. China

E-mail: wangshuyu2013@126.com

Key words: congenital heart defect, extracardiac abnormalities, etiology, chromosomal abnormalities, 22q11 microdeletion disability. Studies in the USA and China have reported that the prevalence of CHD is 4-8 in every 1,000 live births (1-3). This may be as high as 19-74 in every 1,000 live births when particular minor malformations are included, such as bicuspid aortic valves $(4,5)$. The number of reported cases of CHD in China is $1.98-13.8$ per 1,000 live births (6) and in large areas of China, CHDs are the most common birth defects (7). However, these results have been obtained from epidemiological studies within small areas and this area of investigation lacks systematic nation-wide epidemiological research.

CHDs occur due to a number of factors; $90 \%$ of CHDs result from multifactorial disorders, $8 \%$ from single gene disorders and $2 \%$ from environmental teratogens (8). The current predominant method of correcting CHD is through cardiac surgery. The development of techniques and equipment has enabled doctors to execute more complicated heart operations and surgery is performed earlier; where as it used to be conducted in childhood, it is now carried out at the neonatal and even the prenatal stage. Early diagnosis allows surgeons to pay close attention to the classification and severity of the cardiac malformations and to plan treatment accordingly. Notably, 20-45\% children with CHDs also present with extracardiac defects $(9,10)$, which may be caused by genetic factors (11-13). CHDs are commonly observed in fetuses or neonates with chromosomal abnormalities, such as trisomy 21 , trisomy 18 , trisomy 13 , chromosome $4 \mathrm{P}^{-}$syndrome, Cri-du-chat syndrome and DiGeorge syndrome.

22q11 microdeletion syndrome may present as DiGeorge syndrome or velocardiofacial syndrome (also termed conotruncal anomaly face syndrome), and the prevalence is $\sim 1$ in 4,000-6,000 live births $(14,15)$. The syndrome is caused by a microdeletion on chromosome 22 at the q11.2 band. The majority of affected individuals have an identical 3 megabase deletion, which encompasses a region containing 30-40 genes. 22 q11 microdeletion is commonly accompanied by CHD (75-100\% cases), immunodeficiency ( $~ 80 \%$ cases), neonatal hypocalcemia (49-60\% cases), palate anomalies ( $81 \%$ cases, in particular, submucous cleft palate), renal and skeletal anomalies, feeding disorders, growth retardation, speech and language disabilities, and behavioral and psychiatric disorders (14,16-18).

As heart surgery may not improve the prognosis of CHD fetuses with additional problems, it is important to evaluate the requirement for cardiac surgery taking into account the results of genetic screening, and to explore other options, such as termination. Accurate and prompt genetic diagnosis of a fetus with CHDs may aid parents in making such a decision. In the majority 
of countries, chromosome analysis and 22q11 microdeletion detection are commonly investigated in children or adolescents, but are not routinely used on fetuses with CHDs, therefore chromosomal abnormalities may not be detected. A study by Zyblewski et al (19) found that, compared with the severity of the heart defect, the influence of fetal chromosomal abnormality was more significant on the parental decision to terminate the pregnancy or provide special postnatal nursing (20). In China, $>50,000$ CHD surgeries are performed annually (21). Among these, $\sim 50 \%$ of operations are conducted on infants aged 1-2 years. Cardiac surgery is currently following a trend towards operating on younger patients, thus the proportion of surgical procedures performed on newborns is increasing. Appropriate genetic tests are hypothesized to become an important method of diagnosis and vital in evaluating fetal prognosis.

The etiology of CHD may correspond to the area of residence and ethnicity of the patient due to the multiple factors involved in development of the disease. Beijing Obstetrics and Gynecology Hospital (Beijing, China) is the biggest specialist hospital in Obstetrics and Gynecology in the North of China and thus may provide important information regarding the detection of CHD in a large area. The aim of the present study was to analyze chromosomal abnormalities and $22 \mathrm{q} 11$ microdeletions in fetuses with CHD, in order to evaluate fetal prognosis, and to inform the parents and the cardiac surgeons of the result.

\section{Materials and methods}

Study group. The study was conducted between January 2010 and December 2011. Subsequent to obtaining written informed consent, all 113 pregnant females with fetuses with heart malformations detected by routine prenatal diagnostic ultrasound screening that consented to further investigation were enrolled in the study group in the Beijing Obstetrics and Gynecology Hospital (Beijing, China); there were no exclusions. Fetal samples were collected from either amniotic fluid or umbilical cord blood according to gestational age: Amniotic fluid cells were collected from patients with gestational age 16-23 weeks and cord blood cells were collected from patients with gestational age 24-35 weeks. G-banding chromosome karyotyping was performed. The 101 cases with apparently normal chromosomes were then further investigated for the $22 \mathrm{q} 11$ microdeletion following the obtention of written informed consent a second time. The parents of the $22 \mathrm{q} 11$ microdeletion-positive fetuses were then investigated themselves for the same microdeletion. The study was approved by the Beijing Obstetrics and Gynecology Hospital Medical Ethics Committee of Capital Medical University (Approval ID: Ky200912).

Echocardiographic methods. The cardiac defects of all 113 fetuses were diagnosed by certified ultrasound specialists in the prenatal diagnostic center using ultrasound equipment (Philips iU22, GE V730 and Voluson E8; Philips, Amsterdam, The Netherlands). The cardiovascular malformations were screened by a two-dimensional color Doppler appliance (Philips iU22, Amsterdam, The Netherlands) and then confirmed by fetal echocardiography (GE V730, GE, Fairfield, CT, USA). The types of CHD detected were grouped according to 'Fetal heart screening guidelines' (22). Real-time examination included four-chamber, left- and right- heart, long-axis, short-axis, aortic arch and arterial duct views. The different types of cardiac abnormalities were recorded.

Cytogenetic methods. Following genetic consultation and informed consent, amniotic fluid cells were collected from the 48 cases with a gestational age of 16-23 weeks. In addition, cord blood cells were collected from the remaining 65 cases with a gestational age of 24-35 weeks. Chromosomal analysis was conducted using standard methods, including cell culturing, harvesting and histology (23). G-banded metaphase chromosomes were screened at 500-550-band level. The chromosomes were analyzed and karyotyped according to the International System for Human Cytogenetic Nomenclature (ISCN 1995; Fig. 1) and the results were recorded.

Fluorescence in situ hybridization (FISH) methods. FISH analysis of samples collected from the 101 pregnant females whose fetus had normal chromosomes and the 12 parents whose fetus exhibited the 22q11 microdeletion was performed. The analysis was performed on metaphase chromosome spreads using a domestically manufactured probe (Beijing Jinpujia Medical Technology Co., Ltd., Beijing, China), which maps to the TUPLE1 region (22q11.2, spectrum red), combined with the ARSA region (22q11.3, spectrum green) as a control probe $(24,25)$.

FISH analysis was conducted as follows: Following extraction, 5-10 $\mathrm{ml}$ amniotic fluid sample was centrifuged at $900 \mathrm{x} \mathrm{g}$ for $8 \mathrm{~min}$, and the supernatant was removed and discarded. The pelleted cells were incubated in $5 \mathrm{ml}$ hypotonic $0.075 \mathrm{~mol} / \mathrm{l}$ $\mathrm{KCl}$ solution at $37^{\circ} \mathrm{C}$ for $12 \mathrm{~min}$ and then $2 \mathrm{ml}$ Carnoy's fixative (methanol:acetic acid=3:1) was added. The cells were then pelleted by centrifugation at $250 \mathrm{x} g$ for 10 minutes, and fixed twice for 8 min with Carnoy's fixative at room temperature. Fresh Carnoy's fixative was added to adjust the final volume to provide an optimal cell concentration for cell spreading and mixing when the cell suspension was dripped onto a microscope slide. For hybridization, the prepared slides were rinsed twice with $2 \mathrm{X}$ saline-sodium citrate ( $\mathrm{SSC} ; \mathrm{pH} 7.0$ ) for $5 \mathrm{~min}$ at room temperature, treated with $0.1 \mathrm{~mol} / 1 \mathrm{HCl}$ for $5 \mathrm{~min}$, then incubated with pepsin in $0.01 \mathrm{~mol} / 1 \mathrm{HCl}$ at $37^{\circ} \mathrm{C}$ for $12 \mathrm{~min}$. The slides were rinsed again with $2 \mathrm{X} \mathrm{SSC}$ for $5 \mathrm{~min}$ at room temperature, then dehydrated with a series of ethanol dilutions at 70, 85 and $100 \%$ in sequence, air-dried and heated to $56^{\circ} \mathrm{C}$ prior to hybridization. The probe mixture (containing $2 \mathrm{ml}$ probe, $7 \mathrm{ml}$ hybridizing buffer and $1 \mathrm{ml}$ deionized water), was denatured at $76^{\circ} \mathrm{C}$ for $5 \mathrm{~min}$. The slides were denatured separately in $70 \%$ formamide $/ 2 \mathrm{X} \mathrm{SSC}$ at $76^{\circ} \mathrm{C}$ for $5 \mathrm{~min}$ and then dehydrated with $-20^{\circ} \mathrm{C}$ precooled ethanol at 70,85 and $100 \%$ in sequence and air-dried. The denatured probe mixture was dropped onto the cell smear on each prepared slide, covered with a cover slip and sealed with sealing glue. The hybridization was performed in a wet chamber at $42^{\circ} \mathrm{C}$ overnight. On the second day, with the cover slip removed, subsequent to washing three times with $50 \%$ formamide $/ 2 \mathrm{X} \mathrm{SSC}$ at $46^{\circ} \mathrm{C}$ for $10 \mathrm{~min}, 2 \mathrm{X} \mathrm{SSC}$ for $10 \mathrm{~min}$ and $2 \mathrm{X} \mathrm{SSC} / 0.1 \% \mathrm{NP}-40$ for $5 \mathrm{~min}$, the air-dried slides were restained with $15 \mu \mathrm{l}$ 4',6-diamidino-2-phenylindole dihydrochloride for 10-20 min prior to analysis.

The slides were observed with a fluorescence microscope (Olympus BX51; Olympus, Tokyo, Japan); the filters used were MBE44720, MBE45600 and MBE41300. For each specimen, 
A

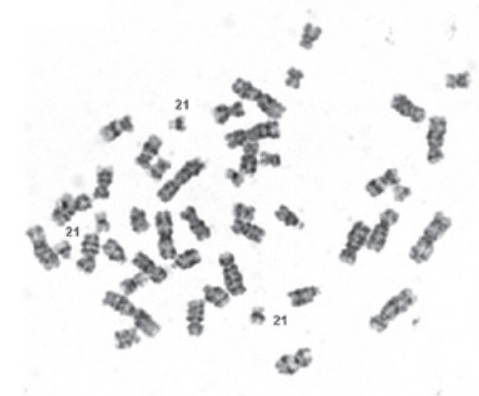

C

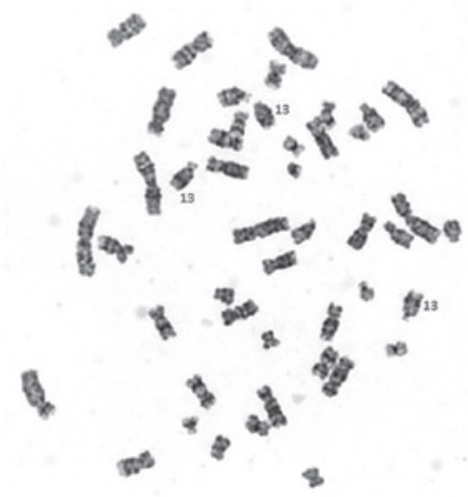

B

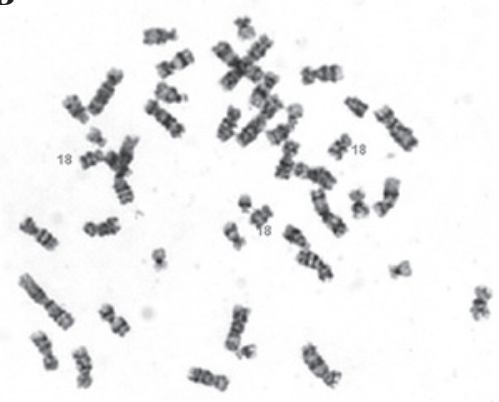

D

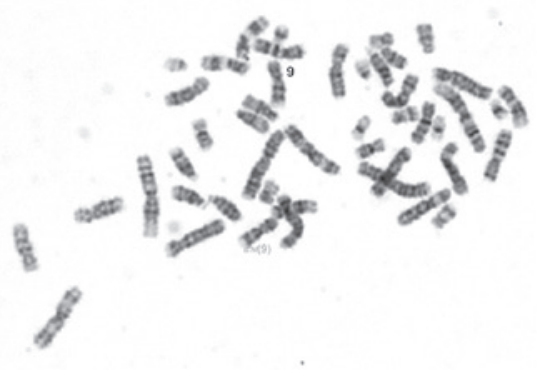

$\mathbf{E}$

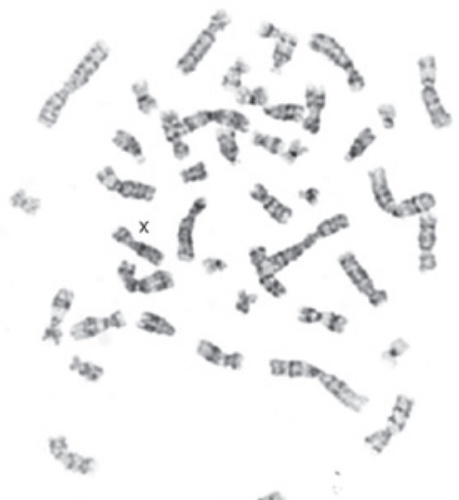

Figure 1. Examples of karyotyping. (A) Trisomy 21 karyotyping (original magnification, x1,000). (B) Trisomy 18 karyotyping (original magnification, x1,000). (C) Trisomy 13 karyotyping (original magnification, x1,000). (D) Inversion 9 karyotyping (original magnification, x1,000). (E) 45, X karyotyping (original magnification, $\mathrm{x} 1,000)$.
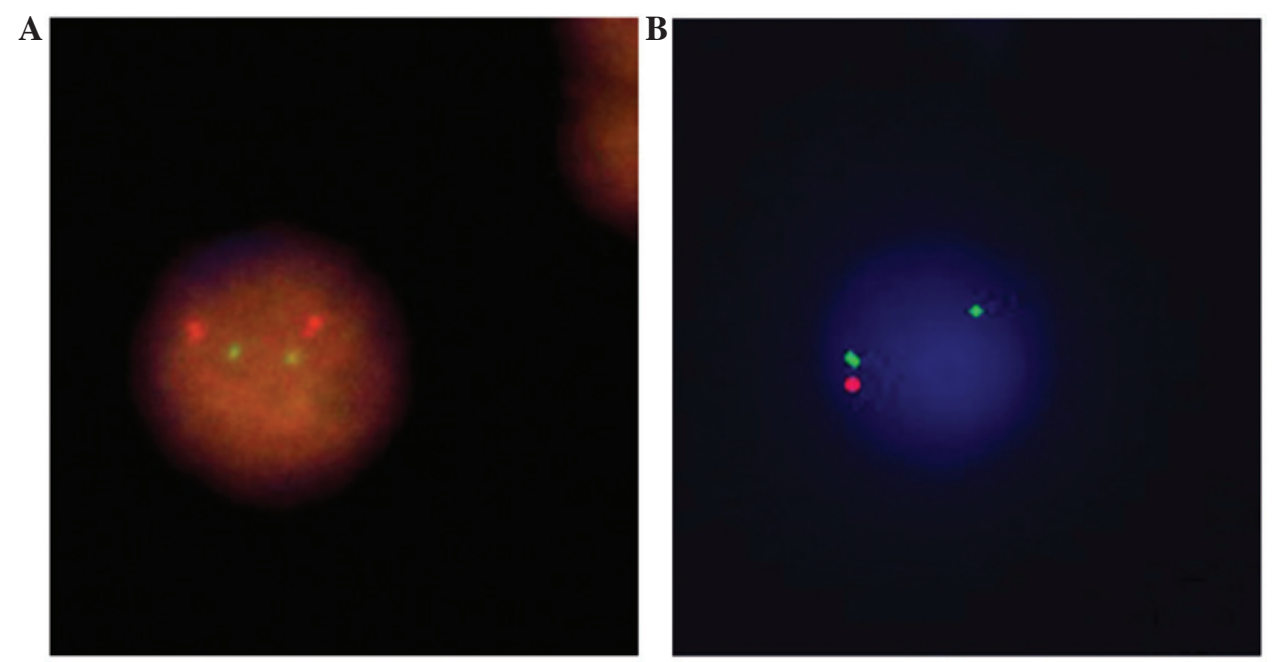

Figure 2. Fluorescence in situ hybidisation using a TUPLE1 probe to the 22q11.2 DNA fragment. (A) Two red and two green signals indicate a normal cell (original magnification, $\mathrm{x} 1,000$ ). (B) One red and two green signals signify a microdeletion of the TUPLE1 gene (original magnification, x1,000). 
Table I. Clinical data for 113 pregnant females carrying fetuses with CHD.

\begin{tabular}{lc}
\hline Factor & Parameter \\
\hline Age, mean \pm SD (range) & $30.73 \pm 4.59(20-47)$ \\
Gestational weeks, mean \pm SD (range) & $25.12 \pm 4.37(16-35)$ \\
Parity, n (\%) & \\
Primipara & $98(86.7)$ \\
Pluripara & $15(13.3)$ \\
Gender of fetus, n $(\%)$ & \\
Male & $67(59.3)$ \\
Female & $42(37.2)$ \\
Unknown & $4(3.5)$ \\
\hline
\end{tabular}

CHD, congenital heart defect; SD, standard deviation.

Table II. Classification of CHDs in 113 fetuses.

\begin{tabular}{|c|c|c|}
\hline Types of CHD & $\mathrm{n}$ & $\%$ \\
\hline \multicolumn{3}{|l|}{ Non-cyanotic } \\
\hline Ventricular septal defect & 47 & 41.6 \\
\hline Atrial septal defect & 11 & 9.7 \\
\hline Pulmonary stenosis & 7 & 6.2 \\
\hline Pulmonary valve stenosis & 4 & 3.5 \\
\hline Aortic stenosis & 2 & 1.8 \\
\hline Aortic valve stenosis & 2 & 1.8 \\
\hline Tricuspid valve dysplasia & 3 & 2.7 \\
\hline Aortic widened & 2 & 1.8 \\
\hline Major blood vessel abnormality & 2 & 1.8 \\
\hline Acleistocardia & 1 & 0.9 \\
\hline \multicolumn{3}{|l|}{ Cyanotic } \\
\hline Tetralogy of Fallot & 17 & 15.0 \\
\hline Endocardial cushion defect & 10 & 8.0 \\
\hline Transposition of the great arteries & 5 & 4.4 \\
\hline Uniatrial heart & 4 & 3.5 \\
\hline Univentricular heart & 4 & 3.5 \\
\hline Hypoplastic left heart syndrome & 4 & 3.5 \\
\hline Truncus arteriosus & 3 & 2.7 \\
\hline Double outlet right ventricle & 2 & 1.8 \\
\hline Hypoplastic right heart syndrome & 2 & 1.8 \\
\hline Total number of fetuses affected & 113 & \\
\hline
\end{tabular}

Fetuses with more than one type of cardiac defect were counted separately. The $\%$ data was determined by the total number of fetuses (113), not by the number of defects (132). CHD, congenital heart defect.

at least 50 nuclei were evaluated. If $90 \%$ cells detected were normal, the specimen was classified as normal (Fig. 2A). If $60 \%$ cells were abnormal, the specimen was diagnosed as affected
Table III. Chromosome analysis and 22q11 microdeletion results of each cardiac defect.

\begin{tabular}{|c|c|c|c|}
\hline \multirow[b]{2}{*}{ Type of CHD } & \multicolumn{2}{|c|}{$\begin{array}{l}\text { Chromosomal } \\
\text { abnormality }\end{array}$} & \multirow{2}{*}{$\begin{array}{l}22 \mathrm{q} 11 \\
\text { microdeletion }(\mathrm{n})\end{array}$} \\
\hline & Type & $\mathrm{n}$ & \\
\hline \multirow[t]{5}{*}{ VSD } & Trisomy 21 & 2 & 2 \\
\hline & Trisomy 18 & 4 & \\
\hline & Trisomy 13 & 1 & \\
\hline & Inv (9) & 1 & \\
\hline & $45, X$ & 1 & \\
\hline PS & Trisomy 21 & 1 & \\
\hline AW & Trisomy 21 & 1 & 1 \\
\hline TOF & Trisomy 18 & 1 & 2 \\
\hline $\mathrm{ECD}$ & Trisomy 21 & 1 & 1 \\
\hline DORV & & & 1 \\
\hline TGA & & & 1 \\
\hline UA & & & 2 \\
\hline UV & & & 2 \\
\hline $\begin{array}{l}\text { Total number of } \\
\text { fetuses affected }\end{array}$ & $12(10.6 \%)$ & & $6(5.3 \%)$ \\
\hline
\end{tabular}

Fetuses with more than one type of cardiac defect were counted separately. The data were determined by the total number of fetuses (113), not the number of defects. CHD, congenital heart defect; VSD, ventricular septal defect; PS, pulmonary stenosis; AW, aortic widened; TOF, tetralogy of Fallot; ECD, endocardial cushion defect; DORV, double outlet right ventricle; TGA, transposition of the great arteries; UA, uniatrial heart; UV, univentricular heart.

(Fig. 2B). In cases where there was any doubt, the number of cells evaluated increased to 100 cells and results were reported as uninformative if the above criteria were not met.

Statistical analysis. The data are presented as the mean \pm standard deviation for continuous variables. Differences in categorical variables were measured using the $\chi^{2}$ test. Analyses were performed with SPSS 17.0 (SPSS, Inc., Chicago, IL, USA). $\mathrm{P}<0.05$ was considered to indicate a statistically significant difference.

\section{Results}

Clinical characteristics of the study group. A total of 113 fetuses with major structural CHD were identified at 16 to $35(25.12 \pm 4.37)$ weeks gestation. The age of the pregnant females ranged between 20 and 47 years (mean, 30.73 \pm 4.59 ). A total of 98 of the pregnant females $(86.7 \%)$ were primipara and the remaining 15 pregnant females were pluripara (13.3\%). A total of 67 fetuses were identified as male and 42 female, while the genders of the remaining 4 were unknown, since terminations of the pregnancies occurred at an early gestational stage. The basic clinical data are listed in Table I. 
Table IV. Genetic testing of fetuses with CHD for extracardiac abnormalities.

\begin{tabular}{lccc}
\hline Extracardiac abnormalities & $\begin{array}{c}\text { Cases }(\mathrm{n}) \\
(\% \text { of group) }\end{array}$ & $\begin{array}{c}\text { Chromosomal abnormalities (n) } \\
(\% \text { of group) }\end{array}$ & $\begin{array}{c}22 \mathrm{q} 11 \text { microdeletion (n) } \\
(\% \text { of group) }\end{array}$ \\
\hline With & $15(13.2)$ & $8(53.3)$ & $1(6.7)$ \\
Without & $98(86.8)$ & $4(4.1)$ & $5(5.1)$ \\
Total & $113(100)$ & $12(10.6)$ & $6(5.3)$ \\
P value & & $<0.001$ & 0.583 \\
\hline
\end{tabular}

CHD, congenital heart defect.

Ultrasound characteristics of study group. The classification of CHDs is determined by the International Paediatric and Congenital Cardiac Code. This divides all types of CHD into 10 categories and 23 subcategories according to a multi-dimensional approach encompassing anatomic, diagnostic and therapeutic criteria (26). Of the fetuses with non-cyanotic cardiac defects, 47 cases (41.6\% of the whole group) of ventricular septal defects (VSD) were identified, followed by 11 cases $(9.7 \%)$ with atrial septal defects (ASD), seven cases $(6.2 \%)$ with pulmonary stenosis, four cases $(3.5 \%)$ with pulmonary valve stenosis, two cases with aortic stenosis, two cases with aortic valve stenosis, three cases with tricuspid valve dysplasia, two cases with aortic widening, two cases with major blood vessel abnormality and one case with acleistocardia.

Of the fetuses with cyanotic cardiac defects, 17 cases $(15.0 \%)$ with tetralogy of Fallot (TOF) were detected, followed by 10 cases $(8 \%)$ with endocardial cushion defects, five cases (4.4\%) with transposition of the great arteries, four cases $(3.5 \%)$ with a uniatrial heart, four cases $(3.5 \%)$ with a univentricular heart, four cases $(3.5 \%)$ with hypoplastic left heart syndrome, three cases with truncus arteriosus, two cases with a double outlet right ventricle and two cases with hypoplastic right heart syndrome. The types and numbers of CHDs are listed in Table II.

CHD type and chromosomal abnormalities in the study group. The associations among CHD type, the incidence of chromosomal abnormalities and the 22q11 microdeletion are shown in Table III. Twelve patients $(10.6 \%)$ had chromosomal abnormalities and 6 patients (5.3\%) exhibited the classic $22 \mathrm{q} 11$ microdeletion.

Table IV reveals the number of the CHD cases that presented with extracardiac abnormalities. The incidence of chromosomal abnormalities was significantly higher in the CHD with extracardiac abnormalities group, than in the CHD without extracardiac abnormalities group $(\mathrm{P}<0.001)$; however, the difference in the incidence of the $22 \mathrm{q} 11$ microdeletion was not significant between these two groups $(\mathrm{P}=0.583)$. The parents of the six fetuses with the $22 \mathrm{q} 11$ microdeletion did not present with the same microdeletion.

\section{Discussion}

The present study was conducted in order to investigate chromosomal abnormalities and the 22 q11 microdeletion in
CHD fetuses in a Chinese population. The genetic results revealed 12 patients $(10.6 \%)$ had chromosomal abnormalities and 6 patients $(5.3 \%)$ exhibited the classic 22q11 microdeletion. Altogether, $\sim 1$ in $6(18 / 113)$ of the CHD cases may be explained by genetic factors. Therefore, genetic factors are likely to be important in CHD etiology.

In total, of the $15 \mathrm{CHD}$ cases exhibiting extracardiac anomalies, eight (53.3\%) had chromosomal abnormalities, while among the remaining $98 \mathrm{CHD}$ cases without extracardiac defects, only four (4.1\%) exhibited chromosomal abnormalities $(\mathrm{P}<0.001)$, suggesting that $\mathrm{CHD}$ fetuses with extracardiac defects are more likely to have chromosomal abnormalities than those fetuses with cardiac defects only. Of the 113 CHD cases, six (5.3\%) were identified to have the 22q11 microdeletion. Among the 15 CHD cases with extracardiac defects, only one $(6.7 \%)$ was found to have the 22 q11 microdeletion, while in the remaining 98 cases without extracardiac defects, five $(5.1 \%)$ exhibited the $22 \mathrm{q} 11$ microdeletion; the difference between the two groups was not significant $(\mathrm{P}=0.583)$. This finding is consistent with the results of studies conducted by Hartman et al (27) and Lammer et al (28), but contradicts those of studies by Fokstuen et al (29) and Borgmann et al (30), who observed that all cases of CHD caused by the 22q11 microdeletion presented with extracardiac defects. However, these authors analyzed unwell infants with CHD, whose extracardiac anomalies were comparatively easy to diagnose; the present study focused on fetuses in the second and third trimesters. Considering the difficulty in ultrasound diagnosis of typical fetal structural malformations, including palate anomalies (particularly submucous cleft palates), renal anomalies and skeletal anomalies, it is difficult to detect all abnormalities during routine ultrasound screening. Song et al (31) demonstrated that as many as $46.4 \%$ of fetal abnormalities are not identified prior to birth. The present study is also not in accordance with the study by Bellucco et al (32), who failed to detect any 22q11.2 deletions. This may be associated with the smaller sample size in that study and ethnic differences in the study populations.

Isolated heart defects, such as ASD, VSD and TOF, are rectified quite well by surgery following birth, with good prognosis. However, an infirm infant with genetic abnormalities commonly presents with a complicated clinical syndrome, with intelligence defects, immunodeficiency and endocrinology abnormalities, as well as behavioral and psychiatric disorders, and the prognosis may not be markedly improved by 
cardiac surgery alone. In the present study, among 47 fetuses with VSDs, 11 (23.4\%) exhibited genetic abnormalities, while in 17 fetuses with TOF, three (17.6\%) had genetic abnormalities. Thus, CHDs accompanied by extracardiac defects should become an indicator of the requirement for chromosome analysis, while fetuses with cardiac defects alone should be an indicator for investigating for the presence of the 22q11 microdeletion during pregnancy. With this extra information, parents are fully informed and consulted as to whether the fetuses will undergo surgery, particularly intrauterine operations; and can make an informed decision regarding termination.

In the present study, the 12 parents of the six fetuses $(5.3 \%)$ with the 22q11 microdeletion exhibited negative results for the same microdeletion, suggesting that these six cases occurred de novo; this is concurrent with previous reports demonstrating that $\sim 90 \%$ microdeletion cases occurred de novo, with no known family history (14). Therefore, routine screening of the parents is not required to detect fetuses that may have this microdeleiton. In the future, the use of novel technology (e.g. chromosomal microarray) may allow more sensitive detection of abnormalities and thus may increase the identified contribution of chromosomal abnormalities further.

The sample size in the present study was relatively small, thus, further studies are required to determine the exact frequency of chromosomal abnormalities and microdeletions, since the etiology of cardiac defects may vary in different ethnic groups.

In conclusion, CHD is currently the most common birth defect in numerous areas of the world, including China, and genetic factors are important in the etiology. As such abnormalities are not rectified without surgery, it is essential to identify the genetic factors involved, including chromosomal abnormalities and the 22q11 microdeletion, a process essential in determining fetal prognosis. These tests provide information allowing appropriate prenatal consultation and assessment of the recurrent risk.

\section{References}

1. Goldmuntz E: The epidemiology and genetics of congenital heart disease. Clin Perinatol 28: 1-10, 2001.

2. American Heart Association: FACTS Small Hearts - Big Challenges Congenital Heart Defects (CHD) in Children, Youth and Adults. http://www.heart.org/idc/groups/heart-public/@ wcm/@adv/documents/downloadable/ucm_304875.pdf. Accessed March 18, 2013.

3. Yang XY, Li XF, Lü XD and Liu YL: Incidence of congenital heart disease in Beijing, China. Chin Med J (Engl) 122: $1128-1132,2009$.

4. Hoffman JI and Kaplan S: The incidence of congenital heart disease. J Am Coll Cardiol 39: 1890-1900, 2002.

5. Gill HK, Splitt M, Sharland GK and Simpson JM: Patterns of recurrence of congenital heart disease: an analysis of 6,640 consecutive pregnancies evaluated by detailed fetal echocardiography. J Am Coll Cardiol 42: 923-929, 2003.

6. Li S, Hong SX and Zhao P: The prevalence of congenital heart defect in small infants of four cities including Shijiazhuang. Chinese Journal of Pediatrics 6: 375-377, 1999 (In Chinese).

7. Zhu H, Kartiko S and Finnell RH: Importance of geneenvironment interactions in the etiology of selected birth defects. Clin Genet 75: 409-423, 2009.

8. Payne RM, Johnson MC, Grant JW and Strauss AW: Toward a molecular understanding of congenital heart disease. Circulation 91: 494-504, 1995.

9. Noonan J: Associated noncardiac malformations in children with congenital heart disease. J Pediatr 63: 468-470, 1963.

10. Greenwood RD, Rosenthal A, Parisi L, Fyler DC and Nadas AS: Extracardiac abnormalities in infants with congenital heart disease. Pediatrics 55: 485-492, 1975.
11. Pierpont ME, Basson CT, Benson DW Jr., et al; American Heart Association Congenital Cardiac Defects Committee; Council on Cardiovascular Disease in the Young: Genetic basis for congenital heart defects: current knowledge: a scientific statement from the American Heart Association Congenital Cardiac Defects Committee, Council on Cardiovascular Disease in the Young: endorsed by the American Academy of Pediatrics. Circulation 115: 3015-3038, 2007.

12. Chaoui R, Körner H, Bommer C, et al: Prenatal diagnosis of heart defects and associated chromosomal aberrations. Ultraschall Med 20: 177-184, 1999 (In German).

13. Paladini D, Russo M, Teodoro A, et al: Prenatal diagnosis of congenital heart disease in the Naples area during the years 1994-1999 - the experience of a joint fetal-pediatric cardiology unit. Prenat Diagn 22: 545-552, 2002.

14. Botto LD, May K, Fernhoff PM, et al: A population-based study of the 22q11.2 deletion: phenotype, incidence, and contribution to major birth defects in the population. Pediatrics 112: 101-107, 2003.

15. Manji S, Roberson JR, Wiktor A, et al: Prenatal diagnosis of 22q11.2 deletion when ultrasound examination reveals a heart defect. Genet Med 3: 65-66, 2001.

16. Goldmuntz E: DiGeorge syndrome: new insights. Clin Perinatol 32: 963-978, 2005.

17. Moore JW, Binder GA and Berry R: Prenatal diagnosis of aneuploidy and deletion $22 \mathrm{q} 11.2$ in fetuses with ultrasound detection of cardiac defects. Am J Obstet Gynecol 191: 2068-2073, 2004.

18. Tan KB, Chew SK and Yeo GS: 22q11.2 deletion syndrome in Singapore (2000-2003): a case for active ascertainment. Singapore Med J 49: 286-289, 2008.

19. Zyblewski SC, Hill EG, Shirali G, et al: Chromosomal anomalies influence parental treatment decisions in relation to prenatally diagnosed congenital heart disease. Pediatr Cardiol 30: 1105-1111, 2009.

20. Soares G, Alvares S, Rocha C, et al: Congenital heart defects and chromosomal anomalies including $22 \mathrm{q} 11$ microdeletion (CATCH 22). Rev Port Cardiol 24: 349-371, 2005.

21. Tang CZ, Zhao H, Gao WG and Hu D: The status of surgical therapy in Congenital heart defect in China. Chin J Evid Based Cardiovasc Med 1: 70-71, 2009 (In Chinese).

22. International Society of Ultrasound in Obstetrics and Gynecology: Cardiac screening examination of the fetus: guidelines for performing the 'basic' and 'extended basic' cardiac scan. Ultrasound Obstet Gynecol 27: 107-113, 2006.

23. Robers E and Warburton S: Laboratory techniques. In: Genetics in Practice: A Clinical Approach for Healthcare Practitioners. Haydon J (ed). Wiley-Blackwell, Hoboken, NJ, pp 49-53, 2007.

24. Jia CW, Wang SY, Ma YM, et al: Fluorescence in situ hybridization in uncultured amniocytes for detection of aneuploidy in 4210 prenatal cases. Chin Med J (Engl) 124: 1164-1168, 2011.

25. Liu T, Liu Q, Wang YX, et al: Use of amniocytes for prenatal diagnosis of 22q11.2 microdeletion syndrome: a feasibility study. Chin Med J (Engl) 123: 438-442, 2010.

26. Houyel L, Khoshnood B, Anderson RH, et al: Population-based evaluation of a suggested anatomic and clinical classification of congenital heart defects based on the International Paediatric and Congenital Cardiac Code. Orphanet J Rare Dis 6: 64, 2011.

27. Hartman RJ, Rasmussen SA, Botto LD, et al: The contribution of chromosomal abnormalities to congenital heart defects: a population-based study. Pediatr Cardiol 32: 1147-1157, 2011.

28. Lammer EJ, Chak JS, Iovannisci DM, et al: Chromosomal abnormalities among children born with conotruncal cardiac defects. Birth Defects Res A Clin Mol Teratol 85: 30-35, 2009.

29. Fokstuen S, Arbenz U, Artan S, et al: 22q11.2 deletions in a series of patients with non-selective congenital heart defects: incidence, type of defects and parental origin. Clin Genet 53: 63-69, 1998.

30. Borgmann S, Luhmer I, Arslan-Kirchner M, Kallfelz HC and Schmidtke J: A search for chromosome 22q11.2 deletions in a series of 176 consecutively catheterized patients with congenital heart disease: no evidence for deletions in non-syndromic patients. Eur J Pediatr 158: 958-963, 1999.

31. Song MS, Hu A, Dyamenahalli U, et al: Extracardiac lesions and chromosomal abnormalities associated with major fetal heart defects: comparison of intrauterine, postnatal and postmortem diagnoses. Ultrasound Obstet Gynecol 33: 552-559, 2009.

32. Bellucco FT, Belangero SI, Farah LM, et al: Investigating 22 q11.2 deletion and other chromosomal aberrations in fetuses with heart defects detected by prenatal echocardiography. Pediatr Cardiol 31: 1146-1150, 2010. 